\section{Factors Associated with Non-Adherence to Antiretro- viral Treatment in Adults at Keetmanshoop District State Hospital in Namibia}

\author{
Temptation Chigova ${ }^{1}$ and Bethabile Lovely Dolamo ${ }^{2^{*}}$ \\ ${ }^{1}$ Keetmanshoop Regional Health Training Centre, Keetmanshoop, Namibia
}

${ }^{2}$ Department of Health Studies, University of South Africa, South Africa

\begin{abstract}
Aim: To identify the factors associated with non-adherence to Antiretroviral Treatment (ART) amongst adult patients at a hospital in Namibia.

Methods: Quantitative and qualitative approaches were employed, study sample of 112 adults aged 21 years and older at Keetmanshoop District State Hospital participated. Adherence to ART was assessed using the pill count and self-report methods. A questionnaire with a Cronbach value of 0.8 was used. Census and multi-stage sampling was applied. Data was collected from August to September 2016 through structured interviews and patients records review. Correlation of variables was done to remove multicollinearity. Stata version 12 was used for logistic regression to do univariate and multivariate analysis to determine factors associated with missing five or more doses.
\end{abstract}

Results: In the univariate analysis the following factors were associated with missing five or more doses: Viral load OR: $5.6,95 \% \mathrm{Cl}: 2.0$ 16.0, Employment OR: 3.3, 95\% Cl: 1.5-7.2, Taking active substance OR: $2.5,95 \% \mathrm{Cl}: 1.3-4.7$ and Emotional status OR: $1.6,95 \% \mathrm{Cl}: 1.02-$ 2.6. The ART stocks seemed adequate as the OR for out of stock did not lead to missed doses (OR: $0.6,95 \% \mathrm{Cl}: 0.4-0.9$ ). Factors such as gender, education, religion and marital status were not associ-

*Corresponding author: Bethabile Lovely Dolamo, Department of Health Stud ies, University of South Africa, Theo van Wijk Building, Preller Street, UNISA South Africa, Tel: +27 8849553218; E-mail: dolamobethabilelovely@gmail.com

Citation: Chigova T, Dolamo BL (2017) Factors Associated with Non-Adherence to Antiretroviral Treatment in Adults at Keetmanshoop District State Hospital in Namibia. J AIDS Clin Res Sex Transm Dis 4: 015.

Received: August 08, 2017; Accepted: December 13, 2017; Published: December 27, 2017 ated with missing five or more doses. After multivariate logistic regression the following factors were associated with missing five or more doses; Taking substance adjusted OR: 3.3, 95\% $\mathrm{Cl}: 1.4-7.6$; WHO clinical stages 2 and 3 adjusted ORs and 95\%Cls: 4.1 (1.2$13.8)$ and 6.1(1.5-25.1) respectively and viral load adjusted OR: 6.3, 95\% Cl: 2.1-18.7. Reasons mentioned by respondents for missed doses included forgetting, alcohol use, poor access to care, work commitments, lack of food, stress and travelling. Of the 112 respondents in the study, $86.6 \%$ had unsuppressed viral loads.

Conclusion: Recommendations includes reinforcing use of reminders, automated SMS, establishing treatment supporters and collaborative efforts in reducing active substance use to improve patient adherence.

Keywords: Adherence; Adult; Antiretroviral (ARV) treatment; Health Belief Model; Human Immuno-deficiency Virus (HIV); Non-adherence.

\section{Background}

Namibia's Anti-Retroviral Therapy (ART) roll out has been very successful, achieving more than $84 \%$ coverage against a national target of $90 \%$ [1]. However, despite the successful role out of ART in Namibia, patients often fail to meet the level of adherence required for successful ART. The challenge of non-adherence to ART treatment has also been noted at the study site. In a study done in Nigeria, outcomes of non-adherence to ARV medication included viral resistance, treatment failure, toxicities and waste of financial resources [2]. Results from a study conducted in Botswana concluded that there is a strong correlation between adherence and clinical outcomes [3]. Given the large number of patients whose HIV infection will progress to AIDS if adherence is suboptimal, research is urgently needed to determine factors influencing adherence so that the most effective interventions to ensure adherence in African cohorts can be employed [4]. In a study in Ethiopia, 26.5\% of the respondents had sub optimal adherence [5]. Locally, a recent study from Northern Namibia reported that $22 \%$ of respondents were non-adherent measured by pill count assessment. Henceforth this study envisaged to identify factors associated with non-adherence to ARV treatment in adult patients at Keetmanshoop hospital in Namibia.

Focusing on the study site, in January 2015, the Keetmanshoop Hospital had 1289 adults receiving ART. On average, the clinic serves about 250 to 400 patients in a month. In the period October to December 2014 a total of 933 patients received follow-up care at the study site. Of these patients $53 \%(\mathrm{n}=530)$ achieved required adherence scores of more than or equal to $95 \%$ while approximately $47 \%$ $(n=403)$ achieved less than the required $95 \%$. The suboptimal adherence rate in $47 \%$ of the patients $36.7 \%$ found in January 2015 at the Keetmanshoop Hospital was significantly higher than that reported in the Northern parts of the country. The Health Belief Model (HBM) was the theory of choice in this study due to its applicability to patient adherence and preventative health practices. The HBM has four major components $[6,7]$. 
Citation: Chigova T, Dolamo BL (2017) Factors Associated with Non-Adherence to Antiretroviral Treatment in Adults at Keetmanshoop District State Hospital in Namibia. J AIDS Clin Res Sex Transm Dis 4: 015.

\section{Perceived susceptibility}

The assumption of the study was that patients whose perception of their susceptibility of HIV disease progression to AIDS is suboptimal may lead to non-adherence to ARV treatment.

\section{Perceived severity}

These personal views of the HIV positive adult that the HIV diagnosis is a serious diagnosis with severe implications to health therefore requires appropriate action like adhering to medicines. This concept has a direct bearing on how the patient will adhere to the ARV treatment. The assumption of the study was that the lower the perception of severity the higher the non-adherence to ARV treatment.

\section{Perceived benefits and Costs}

The individual patient needs to believe that adherence to ART would reduce susceptibility to HIV disease progression and severity. This was the basis for questions in the questionnaire which inquired about how essential ART was to the individual patient. The perceived cost shows that the individual's belief that the materials, physical and psychological costs of adhering to ART are all outweighed the benefits.

\section{Motivation}

This component stresses that even if all components are in place, an individual motivation to take ARVs as prescribed is necessary, absence of which may result in non-adherence. This is influenced by availability of social support (e.g., family members).

\section{Enabling or modifying factors}

The modifying factors include patient satisfaction and socio-demographic factors

\section{Research Methods}

A combination of quantitative and qualitative was used to identify the adherence of participants and investigate the factors associated with non-adherence respectively. Numerical data was used in calculating patient adherence using pill count method and regression analysis on identifying factors statistically significant to non-adherence. Qualitative approach was used in form of a questionnaire to solicit mainly patient reasons for missed doses and their individual comments about service and taking ART.

\section{Population}

Population referred to HIV positive adults receiving HIV care at the Keetmanshoop Hospital. As of January 2015 the total number of adults in care at the hospital was 3568, which included 1289 ART people and 2279 pre-ART people.

\section{Target population}

The target population were HIV positive adults 21 years and older on anti-retroviral treatment at Keetmanshoop Hospital. According to the EPMS of the 1289 patients who were on ART at the site. In the period October to December 2014, 439 patients (47\%) out of 933 who attended the hospital were assessed as being non-adherent to their ARVs as their adherence score according to pill count was less than $95 \%$.

\section{Sampling methods}

Census and multi-stage sampling method was used as shown in the flow chart below in figure 1: Method1sampling procedure. Data collection period was from 3rd August to 7th September 2011.

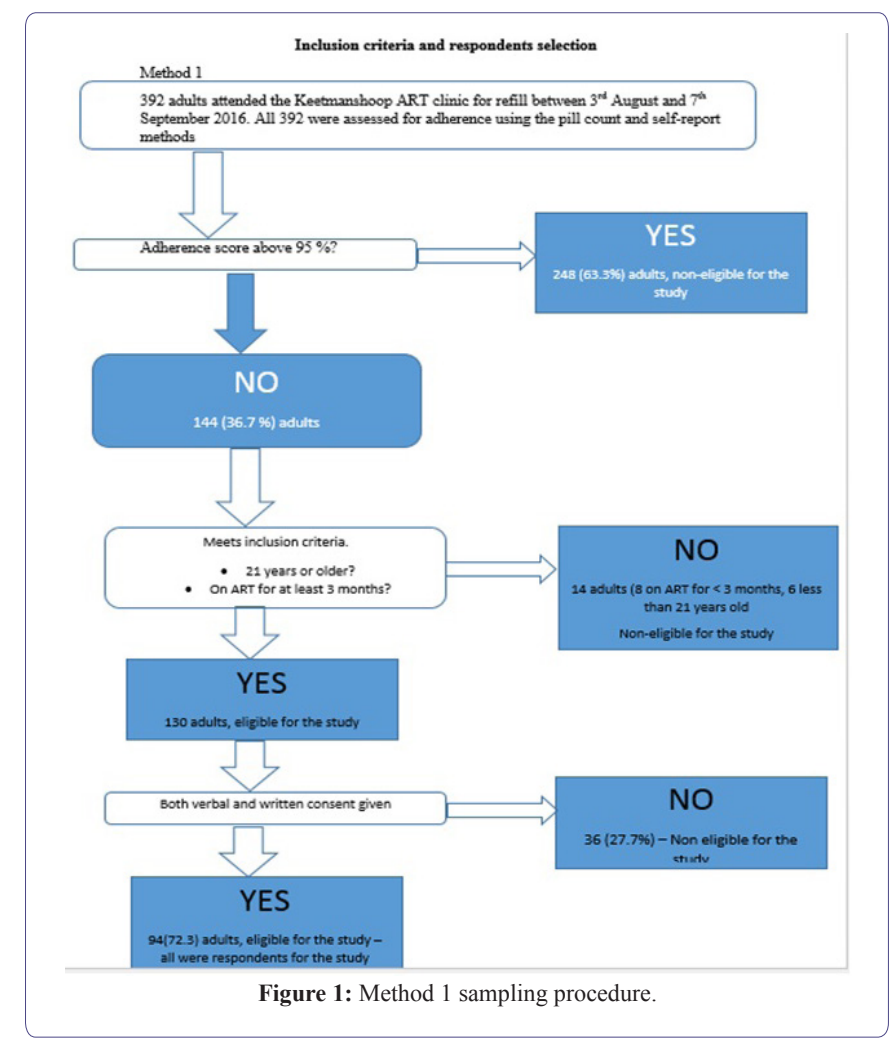

The sample was insufficient and needed additional participants. These were added using review of records method as indicated in the flow chart below figure 2 .

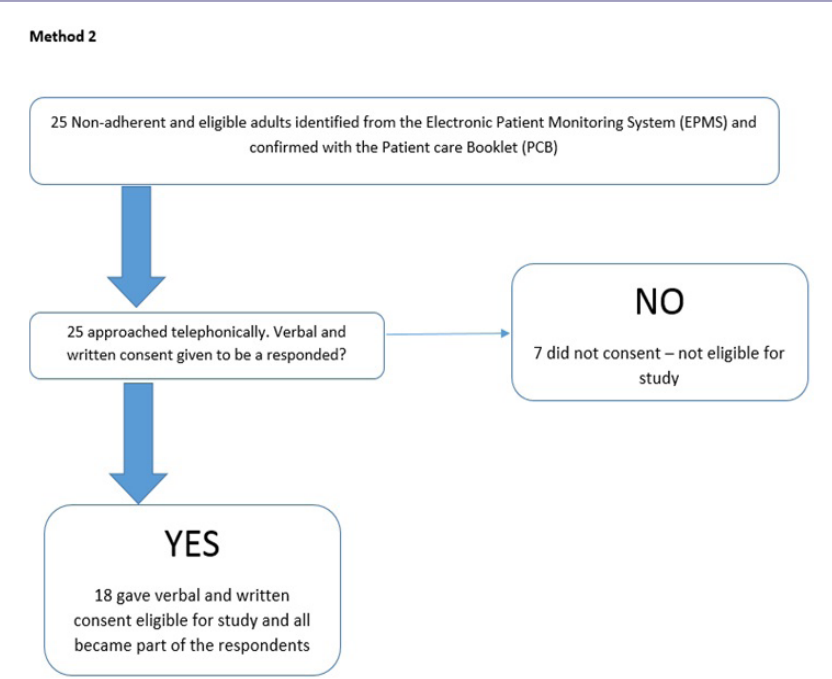

Figure 2: Method 2 sampling procedure for additional participants. 
Citation: Chigova T, Dolamo BL (2017) Factors Associated with Non-Adherence to Antiretroviral Treatment in Adults at Keetmanshoop District State Hospital in Namibia. J AIDS Clin Res Sex Transm Dis 4: 015.

- Page 3 of $7 \bullet$

Altogether 112 adults gave a written consent to participate in the study and these made up the study sample.

\section{Data collection approach and method}

Data collection was through structured interviews supplemented with review of patient records. Information reviewed in the records included the attendances of appointments dates, adherence assessment scores where non-adherence would be identified, ARV regimen of the particular patient, duration on ARV treatment and blood results of patients including the patient viral load.

\section{Development and testing of the data collection instrument}

Whilst the patient adherence was calculated using the pill count and self-report methods, the questionnaire was compiled to investigate factors associated with non-adherence. Data from literature on factors related to non-adherence together with the Namibia HIV Patient Care Booklet (PCB) which is the manual tool in which patient information is entered on every follow-up visit to the clinic were used in questionnaire compilation. The tool was valid in Namibian context and reliable with a Cronbach alpha of 0.80. The questionnaire had 5 subsections; Socio-demographic and socio-economic, Patient-related factors, System-related factors, Disease- and treatment-related factors and Cultural and religious factors.

\section{Data collection process}

Participants were allowed to choose their preferred venue for data collection, $73.3 \%(\mathrm{n}=82)$ of respondents were interviewed at the clinic while $26.7 \%$ where interviewed at places of their choice other than the clinic. Each interview took approximately 10-15 minutes.

\section{Data analysis}

Data was entered in SPSS version 21 and the data was checked for errors and prepared for analysis. Frequencies and graphs were generated. Correlation of variables was done to remove multicollinearity. Stata version 12 was used for logistic regression to do univariate and multivariate analysis to determine factors associated with missing five or more doses.

\section{Results}

The table 1 below summarizes the socio-demographics of the sample.

The analysis of age group and non-adherence of respondents is shown below in figure 3 .

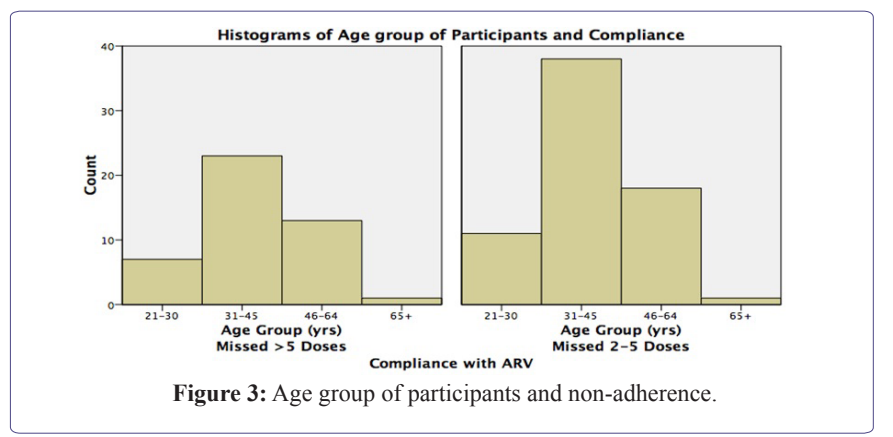

The outcomes of correlation of variables using logistic regression to do univariate and multivariate analysis are shown below in table 2 .

\begin{tabular}{|c|c|c|}
\hline Patient Characteristics & Coding Categories & Number (\%) \\
\hline \multirow{2}{*}{ Sex } & Male & $49(43.8 \%)$ \\
\hline & Female & $63(56.3 \%)$ \\
\hline \multirow{4}{*}{ Age in completed years } & $21-30$ & $18(16.1 \%)$ \\
\hline & $31-45$ & $61(54.5 \%)$ \\
\hline & $46-64$ & $31(27.7 \%)$ \\
\hline & 65 and above & $2(1.8 \%)$ \\
\hline \multirow{4}{*}{ Ethnicity } & Nama-Damara & $53(47.3 \%)$ \\
\hline & Oshiwambo & $53(47.3 \%)$ \\
\hline & Caprivian/Okavango & $5(4.5 \%)$ \\
\hline & Otjiherero & $1(0.9 \%)$ \\
\hline \multirow{6}{*}{ Religion } & Catholic & $30(26.7 \%)$ \\
\hline & Orthodox & $63(56.3 \%)$ \\
\hline & Protestant & $19(17 \%)$ \\
\hline & Islam & 0 \\
\hline & Hindu & 0 \\
\hline & African tradition & 0 \\
\hline \multirow{4}{*}{ Marital status } & Unmarried & $80(71.4 \%)$ \\
\hline & Married & $25(22.3 \%)$ \\
\hline & Separated/Divorced & $5(4.5 \%)$ \\
\hline & Widow or widower & $2(1.8 \%)$ \\
\hline \multirow{4}{*}{ Level of education } & Illiterate & $6(5.4 \%)$ \\
\hline & Basic education & $73(65.2 \%)$ \\
\hline & Elementary education & $5(4.5 \%)$ \\
\hline & College diploma and above & $2(1.8 \%)$ \\
\hline \multirow{4}{*}{ Living condition } & Living alone & $16(14.3 \%)$ \\
\hline & Living with family & $79(70.5 \%)$ \\
\hline & Living with friend & $6(5.4 \%)$ \\
\hline & Living with others & $11(9.8 \%)$ \\
\hline \multirow{4}{*}{ Source of support } & Self-support & $65(58 \%)$ \\
\hline & Families & $36(32.1 \%)$ \\
\hline & NGOS & $7(6.3 \%)$ \\
\hline & No support & $4(3.6 \%)$ \\
\hline \multirow{2}{*}{ Current employment status } & Employed & $55(49.1 \%)$ \\
\hline & Unemployed & $57(50.9 \%)$ \\
\hline
\end{tabular}

Table 1: Socio-demographic and economic characteristics of patients $(\mathrm{n}=112)$.

In the univariate analysis the following factors were associated with missing five or more doses: Viral load OR: 5.6, 95\%CI: 2.0-16.0, Employment OR: 3.3, 95\%CI: 1.5-7.2, Taking active substance OR: 2.5, 95\%CI: 1.3-4.7, and Emotional status OR: 1.6, 95\%CI: 1.02-2.6. The ART stocks seemed adequate as the OR for out of stock did not lead to missed doses (OR: 0.6, 95\% CI: 0.4-0.9). Factors such as gender, education, religion and marital status were not associated with missing five or more doses. After multivariate logistic regression the following factors were associated with missing five or more doses; Taking substance adjusted OR: 3.3, 95\%CI: 1.4-7.6; WHO clinical stages 2 and 3 adjusted ORs and 95\%CIs: 4.1 (1.2-13.8) and 6.1(1.525.1) respectively and viral load adjusted OR: $6.3,95 \%$ CI: 2.1-18.7. Participants taking of active substances and the non-adherence were analyzed and the findings are demonstrated in figure 4 below.

Figure 3 (above) compares missed doses by taking active substances and gender. More women took active substances compared to men and thus were more likely to miss more than five doses compared 
Citation: Chigova T, Dolamo BL (2017) Factors Associated with Non-Adherence to Antiretroviral Treatment in Adults at Keetmanshoop District State Hospital in Namibia. J AIDS Clin Res Sex Transm Dis 4: 015.

to men. Those patients who were self and family supported were more likely to miss their doses compared to those supported by NGOs and those who had no support. The participants' viral load and non-adherence correlation analysis results are illustrated in figure 5 below.

\begin{tabular}{|c|c|c|}
\hline Variable & OR & $95 \% \mathrm{CI}$ \\
\hline Gender & 2.142 & $0.970-4.734$ \\
\hline Age group* & 1.104 & $0.642-1.909$ \\
\hline Ethnicity & 0.673 & $0.361-1.252$ \\
\hline Religion & 0.601 & $0.330-1.095$ \\
\hline Marital status & 1.281 & $0.723-2.271$ \\
\hline Education & 0.989 & $0.574-1.075$ \\
\hline Living conditions & 0.835 & $0.500-1.394$ \\
\hline Viral load & 5.656 & $2.00-15.96^{*}$ \\
\hline Employment & 3.254 & $1.463-7.235^{*}$ \\
\hline ART essential & 0.931 & $0.482-1.797$ \\
\hline Comfortable taking ART & 0.842 & $0.563-1.260$ \\
\hline Active substance & 2.484 & $1.142-5.405^{*}$ \\
\hline Takes substance & 2.516 & $1.338-4.730^{*}$ \\
\hline Disclose to community & 1.855 & $0.783-4.395$ \\
\hline Emotional status & 1.623 & $1.022-2.578^{*}$ \\
\hline ARV remind HIV & 1.356 & $0.788-2.334$ \\
\hline Convenient clinic & 1.576 & $0.964-2.576$ \\
\hline Satisfied with care & 1.08 & $0.608-1.920$ \\
\hline Out of stock & 0.588 & $0.3980-0.869 *$ \\
\hline Experience side effects & 0.714 & $0.391-1.805$ \\
\hline ARV and food & 1.473 & $0.687-3.157$ \\
\hline
\end{tabular}

Table 2: Correlation of variables and non-adherence.

Key: *Statistically significant

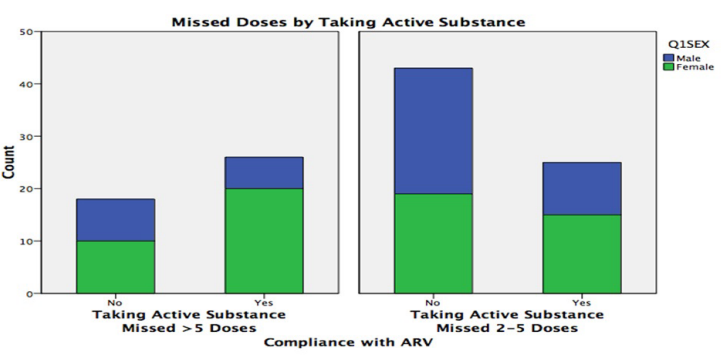

Figure 4: Use of active substances and non-adherence.

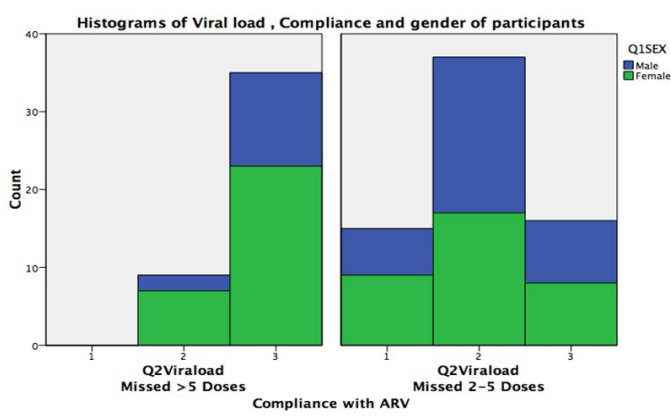

Figure 5: Viral load and non-adherence.
More females had viral load of more than 1000 copies per $\mathrm{ml}$ and missed more females missed more than 5 doses compared to males. Figure 6 below shows the outcomes of correlational analysis of participants WHO clinical stage and non-adherence.

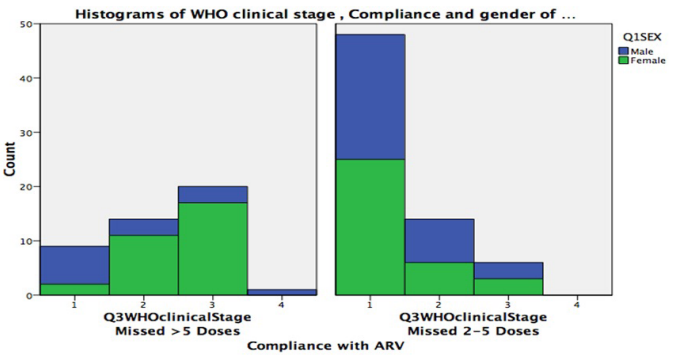

Figure 6: Histograms of WHO clinical stage, compliance and gender.

\section{Respondents' responses on the reason/s for ARV missed dose $(\mathrm{N}=142$, Total $=100 \%)$}

All the 112 respondents in the study were asked for the reasons for missed dose/s. Some respondents mentioned more than one reason. The total number of reasons mentioned by the 112 respondents was 142. However, some reasons were recurring among respondents and were summarized together. Reasons mentioned in the order of most common to least commonly were; forgetfulness $(21.8 \%)$, alcohol use $(15.5 \%)$, challenges in accessing treatment $(9.9 \%)$, work commitments (9.9\%), transport problems to health facility (7\%), lack of food $(4.9 \%)$, stress $(4.2 \%)$ and travelling $(4.2 \%)$. A notable $4.2 \%$ of the respondents mentioned discomfort due to ARVs including the side effects as reason for missed dose.

\section{Discussion}

\section{The level of non-adherence at the study site}

This study concluded that there was an abnormally high non-adherence at the study site warranting corrective interventions. The non-adherence was correlating with a very high number of patients with unsuppressed viral loads. The study results concur with those in another study that showed viral loads are strongly dependent on patient adherence [3].

\section{Factors associated with non-adherence}

The study findings are discussed below under the five subsections of the data collection tool.

\section{Socio-demographic and economic characteristics}

Firstly, the age group of 31-45 was found to be statistically associated with non-adherence. Possibly because most adults in this age group are actively employed which could have increased their chances of missing doses through work commitments, being away from home or being unable to collect their medicines from the clinic. On the contrary, a study in Ethiopia found no association between age and non-adherence [8]. Secondly, employment status also yielded statistical significance with regard to non-adherence. Although an Ethiopian study reported that the likelihood of ART non-adherence in employed patients was 0.41 times that of the unemployed patients, 5 in Northern Namibia employed respondents had a higher rate of adherence 
compared to pensioners and unemployed respondents combined [9]. Gender and educational status did not yield any significance whilst men were more non-adherent than women in the North of the country [9]. Other factors which were statistically insignificant in this study were; ethnicity, religion, marital status, level of education, living condition and source of support. Although in some studies association between marital status and adherence levels were also not established, in Zambia unmarried people were found more non-adherent $[8,10,11]$. Similarly, some studies did not yield any association between education level and adherence levels, but others have documented significance $[8,10,12,13]$. Pertaining to source of support, it is highlighted that there was a significant association between availability of social support in taking ARV treatment and adherence to treatment in Ethiopia [8].

\section{Patient-related factors}

Firstly, active substance abuse came out as a statistically significant factor associated with non-adherence. A little under half of the respondents were into active substances use and $43 \%$ of substance users highlighted they had missed an ARV dose at least once due to the substance use. This is almost double that reported in Northern Namibia where only $22.5 \%$ in the study respondents used active substances [9]. Secondly, patient emotional status also had statistical significance in relation to non-adherence. This study results show that $22 \%$ of the non-adherent adults were depressed while $6(4.2 \%)$ respondents singled stress as a reason for missing ARV doses. Other studies have also concurred that depression is associated with non-adherence [8]. The association between emotional status particularly depression and non-adherence is further re-iterated elsewhere [10].

Factors which were insignificant to non-adherence included; $\mathrm{Pa}$ tient belief that ART is essential for their HIV care, comfortable to take ART in the presence of others, community disclosure and whether the patient feel taking your ARVs reminds them of the HIV infection. On the other hand, it has been recorded that lack of community disclosure is associated with non-adherence [14]. In addition, Gari et al., have also reported that poor beliefs in the benefits of ARVs were associated with non-adherence [15].

\section{System related factors}

The ART stocks were statistically adequate. This meets the Namibia National Drug Policy mandate for the constant availability of safe and efficacious medicines across the Namibian population [16]. Similar findings are reported by Abdissa where the majority (94.2\%) of the respondents had not encountered problems in refilling their ARV drugs at the pharmacy [8]. On the contrary, in Nigeria Uzochukwu et al., reported that non-availability of drugs at treatment sites was one of the factors related to non-adherence [2]. Although, in this study only $50 \%$ of the respondents found the clinic convenient for their care, this did not yield any statistical significance. The remaining two system related factors (convenience of clinic and satisfaction with health care workers) investigated in this study were also statistically insignificant. However, other studies have revealed a significant relationship between perception of study respondents on patient-healthcare worker relationship and their adherence to antiretroviral treatment $[8,17]$.

Additionally, respondents cited some system related barriers as reason for missed doses. These barriers included transportation costs to the clinic, unfriendly service hours and high healthcare worker-patient ratios and the resultant long waiting hours. Similar findings have been reported in Uganda, where transportation costs accounted for $7.8 \%$ of reasons why patients were non-adherent [18]. The association between transport challenges and non-adherence were also reported from other studies [19,20]. As reported in the Presidential Commission of Enquiry, the public health sector suffers from inadequate numbers of staff and availability of equipment and resources [21].

\section{Disease and treatment related factors}

Under this subsection all the fours aspects investigated (duration on ARV treatment, experience of any side effects to ARVs, special instruction regarding ARVs and food and general health status in past 1 month) they were statistically insignificant. Whilst other reports note that taking ART for more than two years was positively associated with adherence in high income countries, others have not yielded any statistically significant association between duration on treatment and adherence to ART $[8,15,22]$. Regarding ARV side effects, they range from minor ones such as nausea, vomiting, skin rash to severe liver damage or life threatening Steven Johnson Syndrome [1]. In this research it was worrisome to note that $57.1 \%$ of respondents were having or had previously suffered from ARV side effects. Uzochukwuet et al., also documents physical side effects of ARVs among reasons for non-adherence [2]. Although only $53.6 \%$ of respondents had special instructions regarding ARVs and food, the majority of respondents believed that they could not take their ARVs when they have not eaten. This belief is contrary to Namibian ART guideline which discourages patients from missing their ARVs because they do not have any food [1]. $4.9 \%$ of this study respondents commented that not having food to take with the ARVs as the reason for missed dose. These findings are similar to those reported by Nghoshi where 7\% of study respondents complained of dietary requirements [9].

While non-adherent respondents would be expected to be sick and with higher WHO clinical stage, only $20 \%$ of the respondents reported being sick in the past one month. The results of non-adherence are cumulative over time, thus respondents who were non-adherent during the data collection period might still have been healthy, but with continual non-adherence, a depleted immune system and rising risk of opportunistic infections would eventually become sick patients with time.

\section{Cultural and religious beliefs related factors}

Similarly all four factors investigated in this section were found to be insignificant statistically. These were; whether taking ARV medicines offend one's cultural beliefs, if HIV infection can be treated by cultural methods without ARV medicines, whether taking ARV medicines offend any of your religious beliefs and if HIV infection can be treated by religious methods without ARV medicines. In a study in Northern Namibian, $11 \%$ of respondents reported taking other traditional treatments together with ART [9]. It is noteworthy that a South African study reports that there is often tension between ARV treatment and alternative therapies [23]. Such beliefs present healthcare workers with a challenge to promote and foster adherence to ART among patients. In an era where some churches offer miracles of different forms, it appears HIV patients have not been spared and are sometimes advised to stop taking the ARVs as a sign of their healing resulting in non-adherence of the part of the patients. 


\section{Respondent's last viral load}

After multivariate logistic regression viral load was statistically related to non-adherence. It is noteworthy that $86.6 \%$ respondents in this study had unsuppressed viral load while only $13.4 \%$ had non-detectable viral loads, also known as maximum viral suppression. On the contrary, in a study in Myanmar, 94\% of patients had an undetectable viral load and only $4 \%$ had ART failure. It is further reported that $84.7 \%$ of respondents on first and second line treatment in the Myanmar study had viral load below 1000 copies/ml [24]. The viral loads in this study support the pill count adherence method as the viral loads depict the adherence level in patients. This is a public threat as resistant HIV strains could result due to the non-adherence [3].

\section{Respondents WHO clinical stage}

Multivariate logistic regression yielded statistical significance in both WHO clinical stages 2 and 3. As noted above, respondents' non-adherence may not have had immediate negative outcomes but the consequences of continual non-adherence are likely to be more prominent over time. In this study, the respondents viral load were already showing non-adherence although the majority of the patients were still in stage 2 .

\section{Respondents' responses on the reason/s for ARV missed dose $(\mathrm{N}=142$, Total $=100 \%)$}

The majority of the reasons were patient related reasons, for example alcohol use, followed by socio-demographic, system of care, disease and treatment and lastly religious reasons. Some of the reasons mentioned in this study, for example forgetfulness, transport problems and work commitments are similar to those reported in other studies $[5,8,9]$. However, while lack of food was mentioned in this study as reason for missed dose, in Northern Namibia, lack of food was not revealed as a reason for missed doses [9]. Due to the Savanna Climate in Northern Namibia, crop farming of staple foods like sorghum is possible which helps to enhance food security in most households. In contrast southern Namibia is predominantly semi-arid to desert which does not support crop farming but mainly small livestock husbandry [25]. Of note also is that, more than half of the respondents in this study were unemployed, which may have impacted on food insecurity among some respondents. As the study site serves a very vast geographic area, is also not surprising that some patients found it very difficult accessing the health facility. A Nigerian study reports that HIV infection related sicknesses constituted 3.5\% of reasons for missed dose, while $2.1 \%$ simply got tired of taking ARVs and missed their doses [2].

\section{Respondents' comments}

The majority of the respondents' comments were directed towards the service delivery system. Main themes derived from the comments included; patients' satisfaction with the services they received from the nurses; although acknowledging inadequacy of nursing staff. Some respondents expressed the need for more nurses to be allocated to the division. Another commonly mentioned suggestion was need for decentralization of ART services so that service can be nearer to the people. Other respondents suggested that the duration of ARV prescription should be increased for up to 6 months to eliminate frequent visits the clinic for refill. Another noteworthy suggestion was towards the integration of ART with other services, including the dispensing of medicines and reviews by a medical officer.

\section{Study recommendations}

The interpretation of the research findings were presented in relation to the Health Belief Model theory and the conceptual framework of the study on factors associated with non-adherence. The HBM theory used in this study assumed that the patient's ability to adhere to ART was strongly dependent on a number of concepts.

Perceived severity: Healthcare workers should use results of viral loads to explain resistance at appropriate levels of understanding of patients as a way to promote understanding of the consequences of non-adherence.

\section{Perceived benefits:}

- Healthcare workers are advised to plot patients' biological markers including CD4 and viral loads on a graph to explain benefits of adherence to patients

- Recruitment and the active involvement of "expert patients" these are HIV positive patients who have disclosed their HIV status and trained to motivate other patients and explaining benefits of adhering to treatment and practicing healthy lifestyle while on ART treatment

\section{Perceived barriers:}

- A multidisciplinary approach is required to help patients to reduce or stop active substance use

- Healthcare workers need to strengthen patients' referral system across the different levels of HIV care so as to make it easier for patients to access continuing care when travelling

- To improve access to ART services for patients in remote areas, ART can be integrated into existing outreach programmes

- Initiate and strengthen effective HIV workplace programs so as to increase awareness among employers on the need for treatment support of employees as well as to reduce stigma which is often experienced at workplaces

- The MoHSS needs to strengthen collaborative efforts with other non-governmental organizations on supportive care for ARV patients such as by providing food support

- Lay counsellors need to be trained in basic communication skills and counselling techniques

\section{Cues to action:}

- Patients should be encouraged to identify treatment supporters of their choice

- The MoHSS is recommended to adopt the use of Automated Short Message Service (SMS) as a way of reminding patients their ARVs Self-efficacy

- Healthcare workers should strengthen health education how to manage in case of missed doses

- There is need to anticipate and discuss potential side effects with patients, the time they maybe experienced and importantly how to handle them

\section{Acknowledgement}

The authors would like to firstly thank God through His Holy Spirit and our Lord Jesus Christ who granted us ability to do this article, 
Citation: Chigova T, Dolamo BL (2017) Factors Associated with Non-Adherence to Antiretroviral Treatment in Adults at Keetmanshoop District State Hospital in Namibia. J AIDS Clin Res Sex Transm Dis 4: 015.

the Keetmanshoop Hospital for permission to conduct study. Also acknowledge, Dr Arthur T. Chigova, for his psychological support throughout the research. Our sincere gratitude to the research statistician Dr. Lovemore Mahachi.

\section{Author Contributions}

BLD contributed to the study design particularly the sampling method and data collection method. Both authors revised the manuscript, gave final approval to the version published and they agree to be accountable for all aspects of the article.

\section{References}

1. Ministry of Health and Social Services (2014) National guidelines for antiretroviral therapy (4thedn). Ministry of Health and Social Services, Windhoek, Namibia.

2. Uzochukwu BS, Onwujekwe OE, Onoka AC, Okoli C, Uguru NP, et al (2009) Determinants of non-adherence to subsidized anti-retroviral treatment in southeast Nigeria. Health Policy Plan 24: 189-196.

3. Ehlers VJ, Tshisuyi ET (2015) Adherence to antiretroviral treatment by adults in a rural area of Botswana. Curationis 38 .

4. Gill CJ, Hamer DH, Simon JL, Thea DM, Sabin LL (2005) No room for complacency about adherence to antiretroviral therapy in sub-Saharan Africa. AIDS 19: 1243-1249.

5. Tsega B, Srikanth BA, Shewamene Z (2015) Determinants of non-adherence to antiretroviral therapy in adult hospitalized patients, Northwest Ethiopia. Patient Prefer Adherence 9: 373-380.

6. Polit DF, Beck CT (2008) Nursing research: Generating and assessing evidence for nursing practice (8thedn). Lippincott Williams \& Wilkins, Philadelphia, USA. Pg no: 796.

7. Eller LS (2009) Adherence, resistance and antiretroviral therapy. Rutgers, The State University of New Jersey, New York, USA.

8. Abdissa AE (2013) Determinant factors affecting adherence to antiretroviral therapy among HIV infected patients in Addis Ababa. University of South Africa, South Africa.

9. Nghoshi SS (2016) Assessment of determinants and levels of adherence to antiretroviral therapy in HIV-infected people in Opuwo district, Kunene region, Namibia. University of Namibia, Windhoek, Namibia.

10. Nachega JB, Mills EJ, Schechter M (2010) Antiretroviral therapy adherence and retention in care in middle-income and low-income countries: current status of knowledge and research priorities. Curr Opin HIV AIDS 5: $70-77$.

11. Sasaki Y, Kakimoto K, Dube C, Sikazwe I, Moyo C, et al. (2012) Adherence to antiretroviral therapy (ART) during the early months of treatment in rural Zambia: influence of demographic characteristics and social surroundings of patients. Ann Clin Microbiol Antimicrob 11: 34
12. Campos LN, Guimarães MDC, Remien RH (2010) Anxiety and depression symptoms as risk factors for non-adherence to antiretroviral therapy in Brazil. AIDS Behav 14: 289-299.

13. Muessig KE, McLaughlin MM, Nie JM, Cai W, Zheng H, et al. (2014) Suboptimal antiretroviral therapy adherence among HIV-infected adults in Guangzhou, China. AIDS Care 26: 988-995.

14. Wasti SP, van Teijlingen E, Simkhada P, Randall J, Baxter S, et al. (2012) Factors influencing adherence to antiretroviral treatment in Asian developing countries: a systematic review. Trop Med Int Health 17: 71-81.

15. Gari S, Doig-Acuña C, Smail T, Malungo JR, Martin-Hilber A, et al (2013) Access to HIV/AIDS care: a systematic review of socio-cultural determinants in low and high income countries. BMC Health Serv Res 13: 198 .

16. Ministry of Health and Social Services (1998) National drug policy for Namibia. Ministry of Health and Social Services, Windhoek, Namibia.

17. De AK, Dalui A (2012) Assessment of factors influencing adherence to anti-retroviral therapy for human immunodeficiency virus positive mothers and their infected children. Indian J Med Sci 66: 247-259.

18. Senkomago V, Guwatudde D, Breda M, Khoshnood K (2011) Barriers to antiretroviral adherence in HIV-positive patients receiving free medication in Kayunga, Uganda. AIDS Care 23: 1246-1253.

19. Biadgilign S, Deribew A, Amberbir A, Deribe K (2009) Barriers and facilitators to antiretroviral medication adherence among HIV-infected paediatric patients in Ethiopia: A qualitative study. SAHARA J 6: 148-154.

20. Tabatabai J, Namakhoma I, Tweya H, Phiri S, Schnitzler P, et al. (2014) Understanding reasons for treatment interruption amongst patients on antiretroviral therapy--a qualitative study at the Lighthouse Clinic, Lilongwe, Malawi. Glob Health Action 7: 24795.

21. Ministry of Health and Social Services (2013) Namibia - Demographic and Health Survey 2013. Ministry of Health and Social Services, Government of Namibia, Windhoek, Namibia.

22. Drachler Mde L, Drachler CW, Teixeira LB, Leite JC (2016) The scale of self-efficacy expectations of adherence to antiretroviral treatment: A tool for identifying risk for non-adherence to treatment for HIV. PLoS ONE 11: 0147443 .

23. Loeliger KB, Niccolai LM, Mtungwa LN, Moll A, Shenoi SV (2016) Antiretroviral therapy initiation and adherence in rural South Africa: community health workers' perspectives on barriers and facilitators. AIDS Care 28: 982-993.

24. Kaleebu P, Kirungi W, Watera C, Asio J, Lyagoba F, et al. (2015) Virological response and antiretroviral drug resistance emerging during antiretroviral therapy at three treatment centers in Uganda. PLoS ONE 10: 0145536.

25. Namibia Statistics Agency (2013) Namibia Population and Housing Census 2011. Namibia Statistics Agency, Government of the Republic of Namibia, Windhoek, Namibia. 